\title{
Survival of Multiple Myeloma Patients Aged 65-70 Years in the Era of Novel Agents and Autologous Stem Cell Transplantation
}

\author{
A Multicenter Retrospective Collaborative Study of the Japanese Society of Myeloma \\ and the European Myeloma Network
}

\author{
Shuji Ozaki ${ }^{\mathrm{a}}$ Takeshi Harada $^{\mathrm{b}}$ Takayuki Saitoh $^{\mathrm{c}}$ Chihiro Shimazaki $^{\mathrm{e}}$ \\ Mitsuhiro Itagaki ${ }^{f}$ Hideki Asaoku $^{\mathrm{f}}$ Yoshiaki Kurodag Takaaki Chou $^{\mathrm{h}}$ \\ Yumiko Yoshiki ${ }^{i}$ Kenshi Suzuki ${ }^{i}$ Hirokazu Murakami ${ }^{c}$ Kunihiko Hayashi ${ }^{d}$ \\ Roberto Minak ${ }^{k}$ Antonio Palumbok Kazuyuki Shimizuj on behalf of the \\ Japanese Society of Myeloma and the European Myeloma Network
}

\begin{abstract}
a Department of Hematology, Tokushima Prefectural Central Hospital, bepartment of Medicine and Bioregulatory Sciences, University of Tokushima, Tokushima, ' Department of Laboratory Sciences, ${ }^{\mathrm{d}}$ Department of Basic Medical Sciences, Gunma University Graduate School of Health Sciences, Gunma, e'Department of Hematology, Social Insurance Kyoto Hospital, Kyoto, ${ }^{\mathrm{f}}$ Department of Hematology, Hiroshima Red Cross Hospital, ${ }^{9}$ Department of Hematology, Hiroshima University Hospital, Hiroshima, h Department of Internal Medicine, Niigata Cancer Center Hospital, Niigata, i'Department of Hematology, Japanese Red Cross Medical Center, Tokyo, and j Japanese Society of Myeloma, Obu, Aichi-prefecture, Japan; ${ }^{\mathrm{k}}$ Department of Hematology, University of Turin, Turin, Italy
\end{abstract}

\section{Key Words}

Autologous stem cell transplantation · Bortezomib · Immunomodulatory drugs $\cdot$ Multiple myeloma

\footnotetext{
Abstract

Novel agents such as thalidomide, lenalidomide and bortezomib have dramatically changed the treatment paradigm of multiple myeloma (MM). However, it is not clear whether these agents improve the prognosis of elderly patients who have undergone autologous stem cell transplantation (autoSCT). We retrospectively analyzed the outcome of 318 newly diagnosed patients aged $65-70$ years who were treated be-
}

tween January 1, 2004, and December 31, 2009. As initial therapy, 192 patients were treated with conventional chemotherapy, 88 with novel agent-containing regimens, 21 with conventional chemotherapy plus auto-SCT and the remaining 17 with novel agents plus auto-SCT. The median progression-free survival was 19.1, 24.5, 26.8 and 35.2 months, respectively, and the 5 -year overall survival (OS) was $40,62,63$ and $87 \%$, respectively. Initial therapy with novel agents $(p<0.001)$ or auto-SCT $(p<0.02)$ significantly improved OS compared with the group without these treatment modalities. Salvage therapy with novel agents also significantly improved survival after relapse compared with conventional chemotherapy alone $(p<0.04)$. In a multivari-

\section{KARGER}

E-Mail karger@karger.com

www.karger.com/aha
C 2014 S. Karger AG, Basel

0001-5792/14/1322-0211\$39.50/0
Shuji Ozaki, MD, $\mathrm{PhD}$

Department of Hematology

Tokushima Prefectural Central Hospital

1-10-3 Kuramoto, Tokushima 770-8539 (Japan)

E-Mail ozaki@tph.gr.jp 
ate analysis, the use of novel agents was an independent prognostic factor significantly associated with extended OS $(p<0.003)$. These results indicate that novel agents and auto-SCT had a major impact on OS in eligible patients in this subgroup of MM.

(C) 2014 S. Karger AG, Basel

\section{Introduction}

Multiple myeloma (MM) is a plasma cell neoplasm characterized by the production of monoclonal immunoglobulin (Ig) and various clinical features such as hypercalcemia, renal failure, anemia and osteolytic bone lesions, as well as immunodeficiency [1]. MM remains incurable; however, the response rate, progression-free survival (PFS) and overall survival (OS) have significantly improved due to the introduction of initial treatment incorporating novel agents such as thalidomide, lenalidomide and bortezomib, and autologous stem cell transplantation (auto-SCT) [2-4]. Based on the results from randomized phase III studies, the National Comprehensive Cancer Network guidelines recommended the use of thalidomide, lenalidomide and bortezomib in the treatment of both transplant-eligible and noneligible patients $[5,6]$. Thus, novel agents have become the standard of care for symptomatic MM as primary therapy and salvage therapy.

Auto-SCT is the standard front-line consolidation therapy, especially for younger patients less than 65 years of age. In elderly patients more than 65 years old, the efficacy and feasibility of an intermediate dose of melphalan $\left(100-140 \mathrm{mg} / \mathrm{m}^{2}\right)$ as a conditioning regimen have been reported previously [7-9]. However, it is not clear whether the combined use of novel agents with auto-SCT translates into better outcome in elderly patients.

To clarify this issue, we retrospectively analyzed the clinical features and treatment outcome of unselected MM patients aged 65-70 years in the facilities of the Japanese Society of Myeloma and the European Myeloma Network.

\section{Methods}

\section{Patients}

Between January 1, 2004, and December 31, 2009, a total of 318 newly diagnosed MM patients aged 65-70 years were treated in 39 facilities of the Japanese Society of Myeloma and the European Myeloma Network. The diagnosis and clinical staging of MM were based on the Durie-Salmon staging system and the International
Staging System (ISS) [10, 11]. Baseline demographics, clinical and laboratory data at diagnosis and information concerning treatment and response were collected retrospectively during January 2012 and May 2012. This survey covered unselected patients treated at the participating facilities, including several patients who had been enrolled in clinical trials, but most patients had been treated in routine practice. This retrospective study was approved by the Ethics Committee/Institutional Review Board of Tokushima Prefectural Central Hospital.

\section{Treatment}

The primary objective was to assess the outcome of patients treated with different initial therapy. Treatment for each patient was determined by the corresponding physician. The shortterm use of dexamethasone for emergent disease control was not considered conventional chemotherapy. Novel agents included thalidomide, lenalidomide and bortezomib in combination with dexamethasone and/or chemotherapeutic agents. AutoSCT was performed as up-front therapy after induction therapy by using a high or intermediate dose of melphalan followed by peripheral blood SCT according to the institutional protocol. The transplantation-related mortality was defined as death due to any cause other than disease progression or relapse within 100 days after transplantation. Clinical response was evaluated according to the international uniform response criteria for MM [12]

\section{Statistical Analysis}

PFS and OS curves were calculated using the Kaplan-Meier estimate, and differences between the curves were evaluated with the log-rank test. The Cox proportional hazards model was used to determine independent predictors associated with extended OS. Variables included baseline patient factors, prognostic factors and treatment-related factors.

\section{Results}

\section{Patients}

A total of 318 patients were studied. There were 167 males and 151 females. The median age was 67 years (range 65-70). The type of monoclonal Ig was IgG in 169 patients, IgA in 80 , light chain in $56, \operatorname{IgD}$ in 7 and others in 6. Performance status of 0,1 and $\geq 2$ were found in 88 , 96 and 93 patients, respectively. Twenty-two patients were classified as Durie-Salmon stage I, 73 as stage II, 216 as stage III and 7 as unknown. With regard to the ISS, 86 patients were stage I, 107 stage II and 102 stage III. Unfortunately, data on cytogenetic abnormalities were not available for most patients.

As initial therapy, 192 patients were treated with conventional chemotherapy, as follows: melphalan + prednisone in 83, vincristine + adriamycin + dexamethasone in 56, high-dose dexamethasone in 25 and other regimens in 28 , including ranimustine + vindesine + mel- 
Table 1. Patient characteristics according to initial therapy

\begin{tabular}{|c|c|c|c|c|c|c|c|c|}
\hline Patients & \multicolumn{2}{|l|}{192} & \multicolumn{2}{|l|}{88} & \multicolumn{2}{|l|}{21} & \multicolumn{2}{|l|}{17} \\
\hline Mean age $\pm S D$, years & \multicolumn{2}{|c|}{$67 \pm 1$} & \multicolumn{2}{|c|}{$67 \pm 1$} & \multicolumn{2}{|l|}{$66 \pm 1$} & \multicolumn{2}{|l|}{$67 \pm 1$} \\
\hline Type of M protein: IgG/IgA/IgD/BJP/other & \multicolumn{2}{|c|}{$104 / 47 / 5 / 31 / 5$} & \multicolumn{2}{|c|}{$45 / 24 / 2 / 16 / 1$} & \multicolumn{2}{|l|}{$10 / 4 / 0 / 7 / 0$} & \multicolumn{2}{|l|}{$10 / 5 / 0 / 2 / 0$} \\
\hline Performance status: $0 / 1 / \geq 2^{\mathrm{a}}$ & \multicolumn{2}{|c|}{$46 / 65 / 76$} & \multicolumn{2}{|c|}{$29 / 16 / 9$} & \multicolumn{2}{|l|}{$6 / 10 / 3$} & \multicolumn{2}{|l|}{$7 / 5 / 5$} \\
\hline ISS: I/II/III & \multicolumn{2}{|l|}{$45 / 62 / 72$} & \multicolumn{2}{|l|}{$23 / 29 / 27$} & \multicolumn{2}{|l|}{$8 / 10 / 2$} & \multicolumn{2}{|l|}{$10 / 6 / 1$} \\
\hline \multirow[t]{5}{*}{ Therapy } & MP & 83 & $\mathrm{BD} / \mathrm{BAD}$ & 33 & $\mathrm{VAD}+\mathrm{sHDM}$ & 9 & $\mathrm{BD}+\mathrm{sHDM}^{\mathrm{e}}$ & 14 \\
\hline & VAD & 56 & MPB & 29 & $\mathrm{VAD}+\mathrm{tHDM}$ & 7 & \multirow{4}{*}{\multicolumn{2}{|c|}{$\mathrm{BD}+\mathrm{tHDM}$}} \\
\hline & HDD & 25 & MPL & 17 & $\mathrm{MP}+\mathrm{sHDM}$ & 2 & & \\
\hline & other ${ }^{\mathrm{d}}$ & 28 & $\mathrm{TD} / \mathrm{MPT}$ & 9 & $\mathrm{MP}$ + tHDM & 1 & & \\
\hline & & & & & HDD + sHDM & 2 & & \\
\hline \multicolumn{9}{|l|}{ Best response } \\
\hline $\mathrm{PR}$ & $85(44 \%)$ & & $33(38 \%)$ & & $5(24 \%)$ & & $5(29 \%)$ & \\
\hline SD & $73(38 \%)$ & & $22(25 \%)$ & & $1(5 \%)$ & & $1(6 \%)$ & \\
\hline PD & $15(8 \%)$ & & $2(2 \%)$ & & $0(0 \%)$ & & $0(0 \%)$ & \\
\hline $\begin{array}{l}\text { Values represent numbers of patients, ex } \\
\text { otherwise. MP = Melphalan + prednisolone; } \\
\text { adriamycin + dexamethasone; HDD = high- } \\
\mathrm{BD}=\text { bortezomib + dexamethasone; BA } \\
\text { adriamycin + dexamethasone; MPB = melph } \\
\text { bortezomib; MPL = melphalan + predniso } \\
\mathrm{TD}=\text { thalidomide + dexamethasone; MPT } \\
\text { nisolone + thalidomide; sHDM = single } \mathrm{h} \\
\text { tHDM = tandem high-dose melphalan; } \mathrm{SD} \\
\text { progressive disease. }\end{array}$ & $\begin{array}{l}\text { pt where ind } \\
\mathrm{AD}=\text { vincris } \\
\text { se dexameth } \\
=\text { bortezon } \\
\mathrm{n}+\text { predniso } \\
\text { e + lenalido } \\
\text { nelphalan + } \\
\text { a-dose melp } \\
\text { cable disease; }\end{array}$ & $\begin{array}{l}\text { icated } \\
\text { tine + } \\
\text { asone; } \\
\text { nib + } \\
\text { lone+ } \\
\text { mide; } \\
\text { pred- } \\
\text { halan; } \\
\text { PD = }\end{array}$ & $\begin{array}{l}{ }^{\mathrm{a}} \text { Data } \\
{ }^{\mathrm{b}} \text { Data } \\
{ }^{\mathrm{c}} \text { Data } \\
{ }^{\mathrm{d}} \text { Othe } \\
\text { prednisol } \\
\text { mustine; } \\
\text { nisolone. } \\
{ }^{\mathrm{e} \text { Two }} \\
\text { patients re }\end{array}$ & $\begin{array}{l}\text { ave } \\
\text { ot ave } \\
\text { egim } \\
\text { e; vi } \\
\text { thyl } \\
\text { atien } \\
\text { eived }\end{array}$ & $\begin{array}{l}\text { lable for } 41 \text { patien } \\
\text { lable for } 7 \text { patient } \\
\text { lable for } 23 \text { patien } \\
\text { ns were: ranimusti } \\
\text { cristine }+ \text { melphal } \\
\text { rednisolone + vin } \\
\text { received } 140 \mathrm{mg} / \\
00 \mathrm{mg} / \mathrm{m}^{2} \mathrm{melpha}\end{array}$ & $\begin{array}{l}\text { ristir } \\
\mathrm{n}^{2} \mathrm{~m} \\
\text { an. }\end{array}$ & $\begin{array}{l}\text { desine }+ \text { melph } \\
\text { examethasone } \pm \\
+ \text { melphalan }+ \\
\text { phalan and the }\end{array}$ & \\
\hline
\end{tabular}

phalan + prednisone, vincristine + melphalan + dexamethasone \pm ranimustine, and methyl prednisone + vincristine + melphalan + prednisone. Another 88 patients were treated with novel agent-containing regimens composed of bortezomib + dexamethasone \pm adriamycin in 33 patients, melphalan + prednisone + bortezomib in 29 , melphalan + prednisone + lenalidomide in 17 , and thalidomide + dexamethasone or melphalan + prednisone + thalidomide in 9. An additional 21 patients were treated with conventional chemotherapy (either vincristine + adriamycin + dexamethasone, melphalan + prednisone or high-dose dexamethasone) plus auto-SCT (13 single SCT and 8 tandem SCT), and the remaining 17 patients were treated with a novel agent-based regimen (bortezomib and dexamethasone) plus auto-SCT (14 single SCT and 3 tandem SCT). As the conditioning regimen before auto-SCT, $140 \mathrm{mg} / \mathrm{m}^{2}$ melphalan was used in 2 patients in the novel agent group and $200 \mathrm{mg} / \mathrm{m}^{2}$ melphalan was used in the remaining 36 patients. Baseline characteristics according to the initial therapy are summarized in table 1 .

\section{Outcome according to Clinical Stage}

We first assessed PFS and OS according to clinical stage. The median PFS for Durie-Salmon stage I, II and III was 40.5, 25.6 and 20.9 months, respectively, and a significant difference was found between stages I and III ( $\mathrm{p}<$ 0.02; fig. 1a). The median OS was 55.2 months for stage III but was not reached in either stage I or II.

As for ISS stage I, II and III, the median PFS was 31.1, 25.0 and 14.2 months, respectively, and significant differences were found between stages I and III ( $p<$ 0.00001 ), and stages II and III ( $\mathrm{p}<0.0003$; fig. $1 \mathrm{~b})$. The median OS was 36.8 months for stage III but was not 


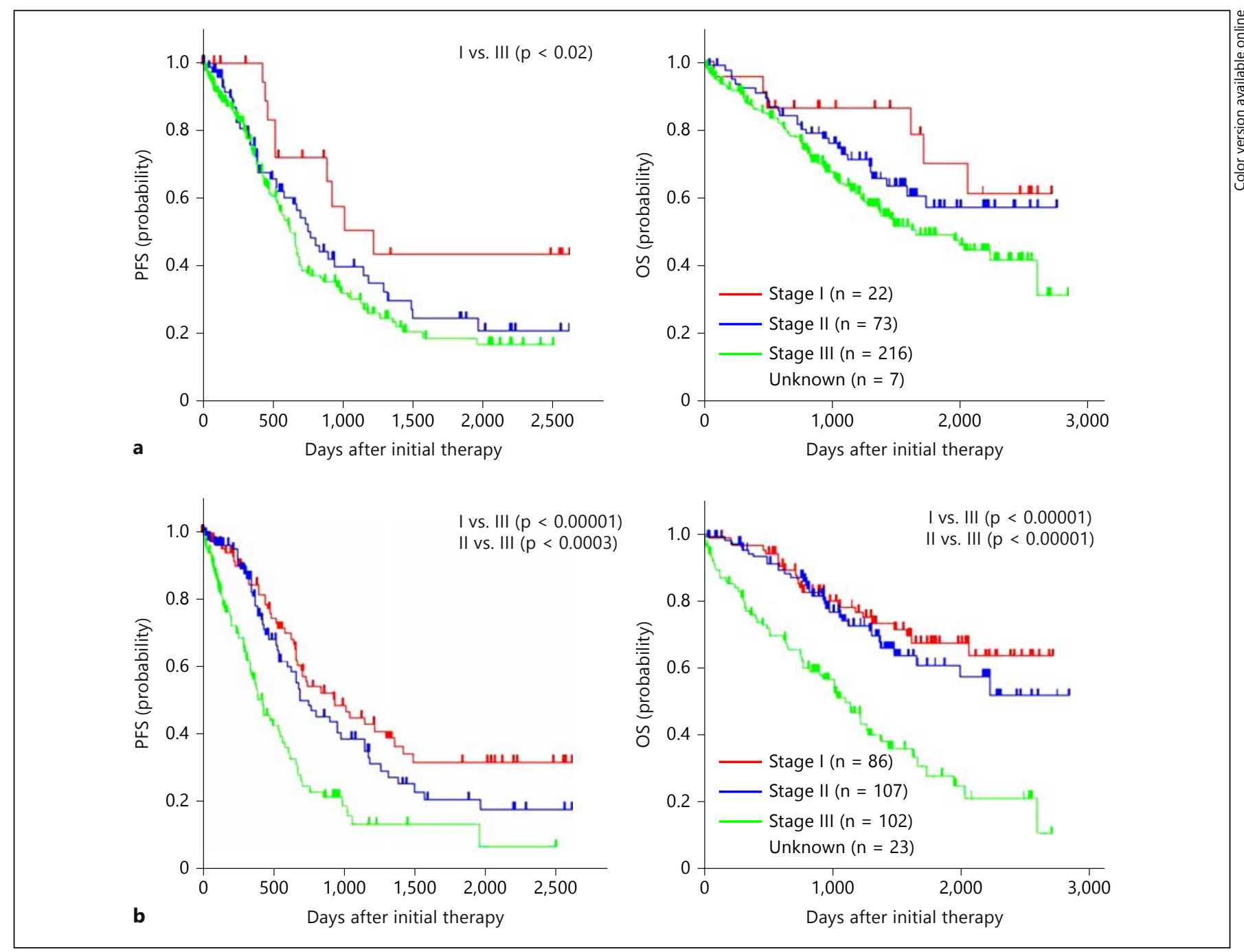

Fig. 1. Outcome according to clinical stage. a PFS and OS according to Durie-Salmon stage. b PFS and OS according to the ISS.

reached in stages I and II. OS was significantly shorter for ISS stage III compared with that for stage I or II ( $\mathrm{p}<$ 0.00001).

\section{Outcome according to Initial Therapy}

We next compared PFS and OS according to initial therapy. The median PFS of the 4 different treatment groups, i.e. conventional chemotherapy, novel agents, conventional chemotherapy plus auto-SCT and novel agents plus auto-SCT, was 19.1, 24.5, 26.8 and 35.2 months, respectively (fig. 2a). PFS was significantly improved in patients treated with a novel agent-containing regimen $(\mathrm{p}<0.01)$ and in those treated with novel agents plus SCT $(p<0.04)$ compared with that of the patients treated with the conventional chemotherapy alone. The median OS of the conventional chemotherapy group was 46.0 months, while it was not reached in the other groups. When we compared the outcome of the conventional chemotherapy group, there was a significant improvement in OS in the following treatment groups: novel agent-containing regimen $(\mathrm{p}<0.001)$, chemotherapy plus SCT $(\mathrm{p}<0.02)$ and novel agents plus SCT $(\mathrm{p}<0.02)$. In terms of auto-SCT or novel agents as the front-line treatment, the median OS was significantly improved in the auto-SCT group compared with the non-SCT group (not reached vs. 57.9 months, $\mathrm{p}<0.02$ ) and more so in the novel agents group compared with the non-novel agents group (not reached vs. 49.3 months, $\mathrm{p}<0.001$; fig. $2 \mathrm{~b}$ ). No transplantation-related mortality was observed. 


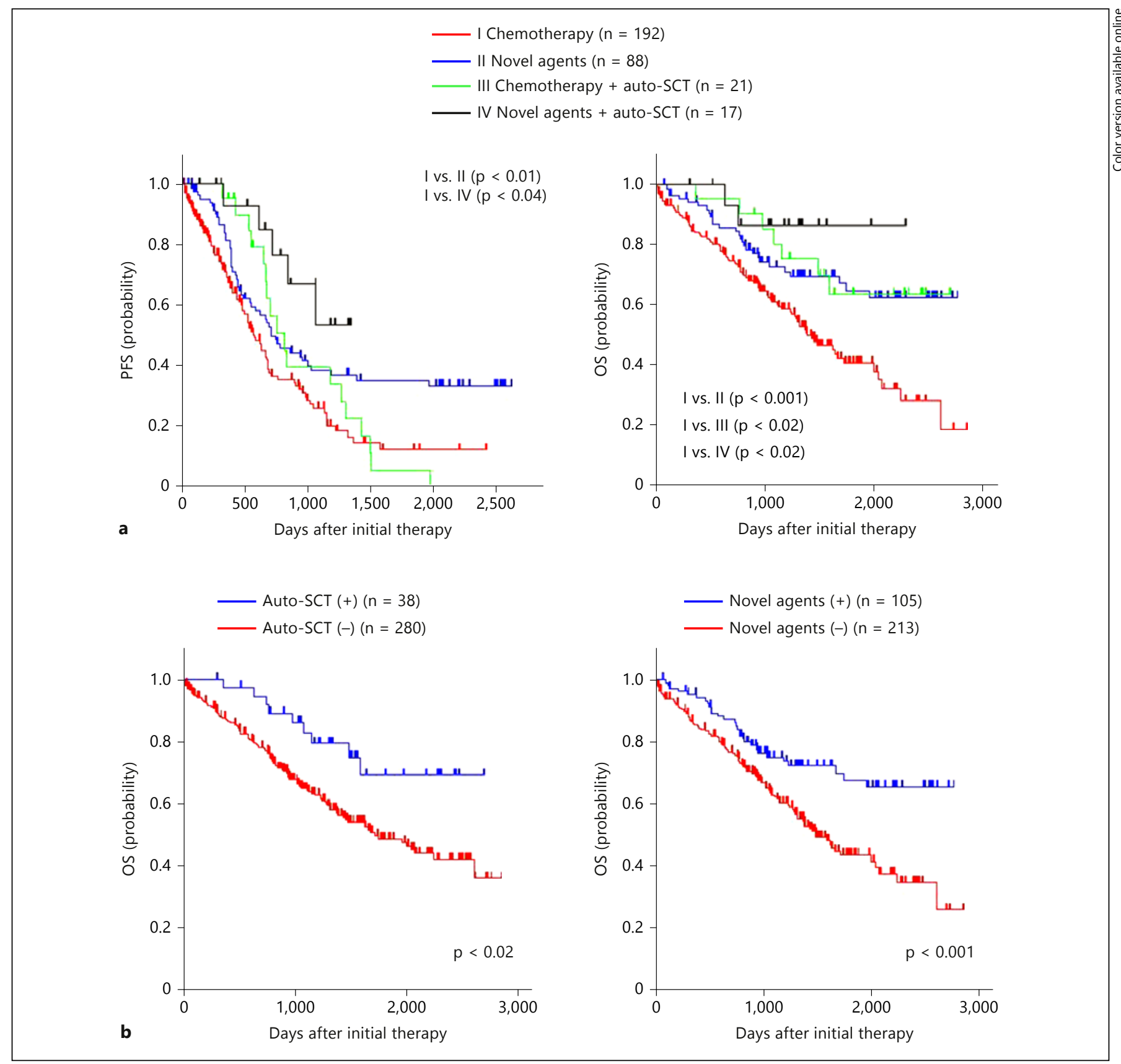

Fig. 2. Outcome according to initial therapy. a PFS and OS according to initial therapy, i.e. either conventional chemotherapy, novel agents, conventional chemotherapy plus auto-SCT or novel agents plus auto-SCT. b OS of patients treated with first-line auto-SCT or novel agents.

\section{Efficacy of Novel Agents on OS}

Because the induction therapy with novel agents had a significant impact on OS, we further evaluated the impact of novel agents as salvage therapy. When we analyzed OS in terms of the use of novel agents, the median OS was significantly improved in the group of patients treated with novel agents either as first-line or salvage therapy (second- and third-line) compared with those treated with conventional chemotherapy alone [86.7 months $(\mathrm{n}=232)$ vs. 38.0 months $(\mathrm{n}=86), \mathrm{p}<0.0001$; fig. 3a]. Among 168 relapsed patients who received either conventional chemotherapy, novel agents or auto-SCT as ini- 


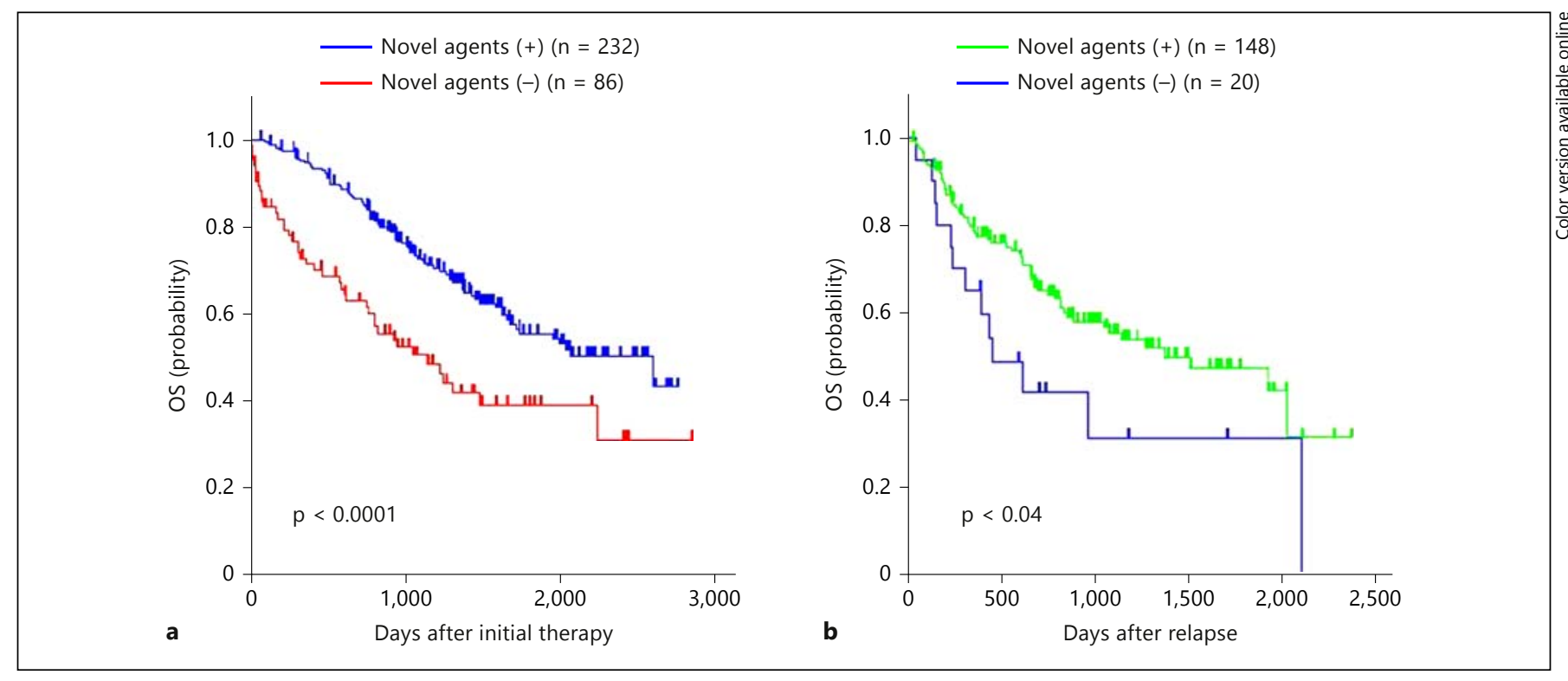

Fig. 3. Efficacy of novel agents on OS. a OS of patients treated with at least one novel agent-containing regimen during the clinical course. b Survival after relapse for relapsed patients treated with either conventional chemotherapy or novel agents as salvage therapy.

tial therapy, 148 patients were treated with novel agentcontaining regimens and the remaining 20 patients with conventional chemotherapy alone as salvage therapy. The median survival from the time of relapse was significantly extended in the novel agent group (45.5 months) compared with the chemotherapy group (15.0 months, $\mathrm{p}<$ 0.04 ; fig. $3 \mathrm{~b}$ ). No patient was treated with auto-SCT as salvage therapy.

\section{Outcome according to Response}

The best response to treatment in the 318 patients was a complete response (CR) in 26 patients (8.2\%), very good partial response (VGPR) in $56(17.6 \%)$, partial response (PR) in 127 (39.9\%), stable disease in 92 (28.9\%) and disease progression in 17 (5.3\%). Achievement of CR or VGPR was mostly observed in patients treated with autoSCT (table 1). A significant difference in OS was found between the CR and PR groups $(\mathrm{p}<0.003)$ and between the VGPR and PR groups ( $\mathrm{p}<0.05$; fig. 4$)$.

\section{Multivariate Analysis}

Finally, we performed a multivariate analysis to identify predictors independently associated with OS by using the Cox proportional hazards model. Variables included in the analysis were baseline patient factors (age, gender and type of $M$ protein), prognostic factors (albumin, $\beta_{2}$-microglobulin and ISS stage) and treatment-related factors (the use of novel agents and auto-SCT). In

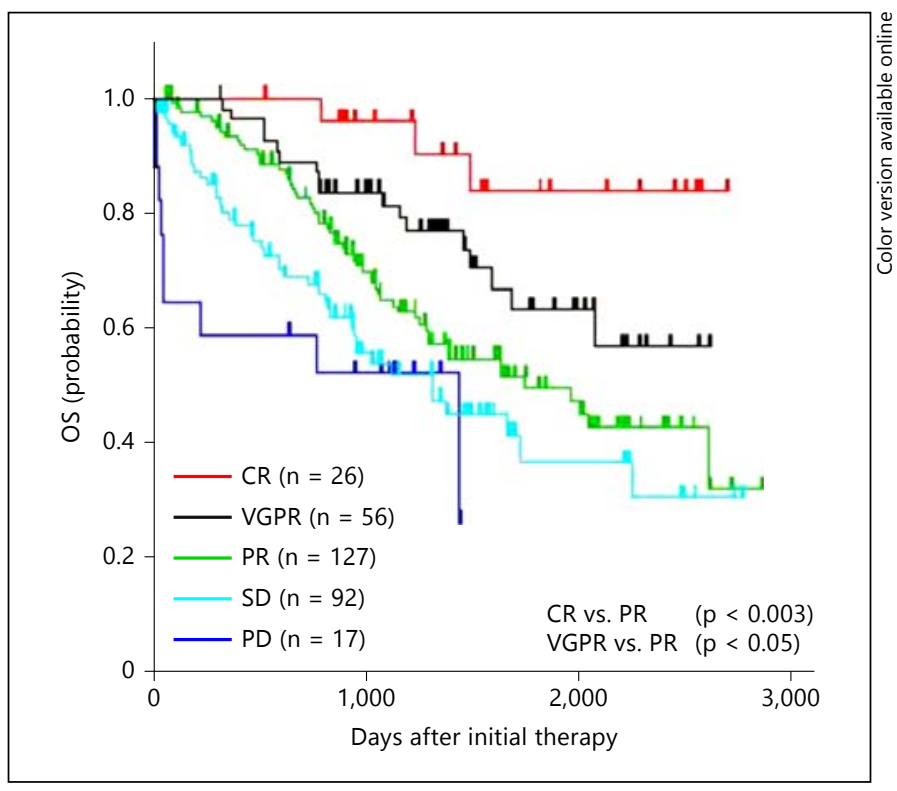

Fig. 4. Outcome according to response. OS according to best response, i.e. CR, VGPR, PR, stable disease (SD) or progressive disease (PD).

this analysis, serum albumin $(\mathrm{p}<0.00005)$ and $\beta_{2^{-}}$ microglobulin $(\mathrm{p}<0.02)$ were important prognostic factors for OS (table 2). As for the type of M protein, the BJP type $(\mathrm{p}<0.01)$ was found to be a significant prognostic factor associated with poor OS. Among treatment-relat- 
Table 2. Multivariate analysis for OS

\begin{tabular}{lcccc}
\hline Variable & $\beta$ & SE $(\beta)$ & $Z$ & p value \\
\hline Age & 0.10093 & 0.07053 & 1.43112 & 0.1524 \\
Gender & -0.0239 & 0.19621 & 0.12176 & 0.9031 \\
Type of M protein & -0.7012 & 0.26077 & 2.68887 & 0.0072 \\
Albumin & -0.7308 & 0.15411 & 4.74216 & $<0.00005$ \\
$\beta_{2}$-Microglobulin & 0.02670 & 0.01110 & 2.40455 & 0.0162 \\
ISS stage & 0.17161 & 0.15183 & 1.13021 & 0.2584 \\
Novel agent & -0.6770 & 0.22269 & 3.04012 & 0.0024 \\
Auto-SCT & -0.5614 & 0.38184 & 1.47022 & 0.1415 \\
\hline
\end{tabular}
mib.

Novel agents included thalidomide, lenalidomide and bortezo-

ed factors, the use of novel agents $(\mathrm{p}<0.003)$ was an independent favorable predictor significantly associated with extended OS.

\section{Discussion}

In this study, we performed a retrospective analysis of the prognosis of newly diagnosed MM patients aged 6570 years. We evaluated an unselected group of patients who had been treated between January 1, 2004, and December 31, 2009. During this period, novel agents such as thalidomide, lenalidomide and bortezomib were available in clinical trials and routine practice. Therefore, this survey allowed us to compare the difference in outcome in terms of the use of novel agents.

Our data have shown that front-line therapy with novel agents or auto-SCT significantly prolonged OS when compared with conventional chemotherapy alone and that the use of novel agents followed by auto-SCT consolidation further improved OS. The additional use of novel agents as salvage therapy also prolonged the survival period after relapse. These findings suggest that treatment with novel agents and auto-SCT were effective approaches in this subgroup of MM patients.

In the current study, treatment for each patient was determined by the corresponding physician, and the baseline patient characteristics were different between each treatment group according to initial therapy. Therefore, the results cannot be compared equally across the groups. At that time, novel agents, especially bortezomib, were not used in vulnerable patients with performance status $\geq 3$ because of the possibility of severe adverse events such as interstitial pneumonitis [13]. Thus, there

Extended Survival of Elderly Myeloma Patients was a bias in the patient background; that is, the conventional chemotherapy group included more fragile patients compared with the novel agent-containing regimen group or the auto-SCT group. Nevertheless, the median PFS in the conventional chemotherapy group was 19.1 months, which is similar to the previous data observed in clinical trials of melphalan + prednisone or other conventional chemotherapy (approximately 18 months) [14]. This suggests that the treatment outcome in the conventional chemotherapy group was not inferior to that in the historical standard chemotherapy group. Taken together, our results rather indicate a possible survival benefit of novel agents and auto-SCT in particular eligible patients.

We also found that the median OS in the conventional chemotherapy group (46.0 months) was longer than that in previous clinical trials (29 months) [14]. This is most likely due to the improvement of salvage therapy with novel agents. In fact, the survival after relapse was significantly improved by novel agent-containing regimens compared with conventional chemotherapy alone regardless of the use of novel agents as initial therapy. These findings also support the efficacy of novel agents as salvage therapy in MM.

Auto-SCT has been mostly applied to younger patients aged 65 or younger. Nevertheless, in this survey, 38 of 318 patients (12\%) aged 65-70 years had been successfully managed with auto-SCT without transplantation-related mortality. Our results suggest that auto-SCT is a safe and effective approach for eligible patients with a good health condition, and this transplant eligibility in the elderly population is another prognostic factor for extended OS. Thus, auto-SCT is still an important strategy for so-called transplant-ineligible patients, as was reported previously [7, 9].

Recent treatment strategies with novel agents have significantly improved response rates in both younger and elderly patients with MM [15-18]. The achievement of CR and VGPR has been shown to be associated with prolonged PFS and OS in both transplant-eligible and -ineligible patients $[3,4]$. In this study, CR and VGPR were mostly observed in the groups of patients treated with novel agents and/or auto-SCT, and these patients exhibited significantly longer OS compared with those achieving PR or inferior responses. Thus, the achievement of CR or VGPR was another favorable factor associated with extended OS, regardless of initial therapy.

By multivariate analysis, we confirmed that serum albumin and $\beta_{2}$-microglobulin were independent prognostic factors for OS. Among the types of M protein, the BJP type was related to a poor prognosis. The reason is probably because most patients with BJP type had the compli- 
cation of renal damage. As for the treatment, the use of novel agents was an independent favorable prognostic factor associated with extended OS. Treatment with autoSCT was not a significant prognostic factor, probably due to the small number of patients treated with auto-SCT.

In conclusion, our results indicate that treatment with novel agents and auto-SCT had a major impact on OS in eligible patients aged $65-70$ years. We should evaluate the possible clinical indications of using novel agents plus auto-SCT even in this subgroup of elderly patients with MM.

\section{Acknowledgements}

We thank the physicians and medical staff who participated in this study. Study investigators are listed below.

\section{The Japanese Society of Myeloma}

Masayo Yamamoto, Division of Gastroenterology and Hematology/Oncology, Department of Medicine, Asahikawa Medical University, Asahikawa; Takayoshi Miyake and Yasutaka Kakinoki, Department of Hematology, Asahikawa City Hospital, Asahikawa; Toshiaki Hayashi, First Department of Internal Medicine, Sapporo Medical University School of Medicine, Sapporo; Seiji Shida, Department of Hematology, Nephrology and Rheumatology, Akita University Graduate School of Medicine, Akita; Shigeki Ito, Hematology and Oncology, Department of Internal Medicine, Iwate Medical University School of Medicine, Morioka; Tohru Izumi, Division of Hematology, Tochigi Cancer Center, Utsunomiya; Takaaki Chou, Department of Internal Medicine, Niigata Cancer Center Hospital, Niigata; Hiroshi Handa, Department of Medicine and Clinical Sciences, Gunma University Graduate School of Medicine, Maebashi; Takayuki Saito and Hirokazu Murakami, Department of Laboratory Sciences, Gunma University Graduate School of Health Sciences, Maebashi; Morio Sawamura, Department of Hematology, National Hospital Organization Nishigunma National Hospital, Shibukawa; Kyoya Kumagai, Division of Hematology-Oncology, Chiba Cancer Center Hospital, Chiba; Shinya Okuda, Department of Hematology, Saitama Citizens Medical Center, Saitama; Go Yamamoto, Department of Hematology and Oncology, Graduate School of Medicine, The University of Tokyo, Tokyo; Makoto Sasaki, Department of Hematology, Juntendo University School of Medicine, Tokyo; Yumiko Yoshiki and Kenshi Suzuki, Department of Hematology, Japanese
Red Cross Medical Center, Tokyo; Tomonori Nakazato, Department of Hematology, Yokohama Municipal Citizens Hospital, Yokohama; Naohi Sahara, Department of Hematology, Kanto Rosai Hospital, Kawasaki; Shinsuke Iida, Department of Medical Oncology and Immunology, Nagoya City University Graduate School of Medical Sciences, Nagoya; Toshiya Adachi, Department of Hematology, Social Insurance Chukyo Hospital, Nagoya; Hiroyuki Takamatsu, Department of Hematology, School of Medicine, Kanazawa University, Kanazawa; Toshihiro Fukushima, Department of Hematology and Immunology, Kanazawa Medical University, Kahoku; Akiyo Yoshida, Department of Hematology, Ishikawa Prefectural Central Hospital, Kanazawa; Hiroyuki Takamatsu, Department of Internal Medicine, NTT West Kanazawa Hospital, Kanazawa; Junya Kuroda, Division of Hematology and Oncology, Department of Medicine, Kyoto Prefectural University of Medicine, Kyoto; Mayumi Hatsuse and Chihiro Shimazaki, Department of Hematology, Social Insurance Kyoto Hospital, Kyoto; Hideo Yagi, Department of Hematology, Nara Hospital Kinki University Faculty of Medicine, Ikoma; Hiroshi Gomyo and Tohru Murayama, Hematology Division, Department of Medicine, Hyogo Cancer Center, Akashi; Takashi Sonoki, Department of Hematology/Oncology, Wakayama Medical University, Wakayama; Kazutaka Sunami, Division of Hematology, Department of Internal Medicine, National Hospital Organization Okayama Medical Center, Okayama; Kosuke Kimura, Taro Masunari, Toru Kiguchi and Nobuo Sezaki, Department of Hematology, Chugoku Central Hospital, Fukuyama; Yoshiaki Kuroda, Department of Hematology, Hiroshima University Hospital, Hiroshima; Mitsuhiro Itagaki and Hideki Asaoku, Department of Hematology, Hiroshima Red Cross Hospital, Hiroshima; Takaaki Miyake, Department of Hematology, Shimane University Hospital, Izumo, Shimane; Toshio Wakayama, Department of Hematology and Oncology, Shimane Prefectural Central Hospital, Izumo; Kimihiro Kawakami, Department of Hematology, Kagawa Prefectural Central Hospital, Takamatsu; Takeshi Harada and Masahiro Abe, Department of Medicine and Bioregulatory Sciences, The University of Tokushima Graduate School, Tokushima; Shuji Ozaki, Etsuko Sekimoto, Hironobu Shibata and Toshio Shigekiyo, Department of Hematology, Tokushima Prefectural Central Hospital, Tokushima; Naokuni Uike, Department of Hematology, National Kyushu Cancer Center, Fukuoka, and Hiroyuki Hata, Department of Hematology, Kumamoto University, Kumamoto, Japan.

The European Myeloma Network

Roberto Mina and Antonio Palumbo, Department of Hematology, University of Turin, Turin, Italy.

\section{References}

1 Palumbo A, Anderson K: Multiple myeloma. N Engl J Med 2011;364:1046-1060.

-2 Kumar SK, Rajkumar SV, Dispenzieri A, Lacy MQ, Hayman SR, Buadi FK, Zeldenrust SR, Dingli D, Russell SJ, Lust JA, Greipp PR, Kyle RA, Gertz MA: Improved survival in multiple myeloma and the impact of novel therapies. Blood 2008;111:2516-2520.

-3 Martinez-Lopez J, Blade J, Mateos MV, Grande C, Alegre A, Garcia-Larana J, Sureda
A, de la Rubia J, Conde E, Martinez R, de Arriba F, Viguria MC, Besalduch J, Cabrera R, Gonzalez-San Miguel JD, Guzman-Zamudio JL, Gomez del Castillo MC, Moraleda JM, Garcia-Ruiz JC, San Miguel J, Lahuerta JJ; Grupo Espanol de MM; Programa para el Estudio de la Terape utica en Hemopatia M: Long-term prognostic significance of response in multiple myeloma after stem cell transplantation. Blood 2011;118:529-534.
4 Gay F, Larocca A, Wijermans P, Cavallo F, Rossi D, Schaafsma R, Genuardi M, Romano A, Liberati AM, Siniscalchi A, Petrucci MT, Nozzoli C, Patriarca F, Offidani M, Ria R, Omede P, Bruno B, Passera R, Musto P, Boccadoro M, Sonneveld P, Palumbo A: Complete response correlates with long-term progression-free and overall survival in elderly myeloma treated with novel agents: analysis of 1,175 patients. Blood 2011;117:3025-3031. 
$>5$ Anderson KC, Alsina M, Bensinger W, Biermann JS, Chanan-Khan A, Cohen AD, Devine S, Djulbegovic B, Faber EA Jr, Gasparetto C, Huff CA, Kassim A, Medeiros BC, Meredith R, Raje N, Schriber J, Singhal S, Somlo G, Stockerl-Goldstein K, Treon SP, Tricot G, Weber DM, Yahalom J, Yunus F: Multiple myeloma. J Natl Compr Canc Netw 2011;9:1146-1183.

$\checkmark 6$ Anderson KC, Alsina M, Bensinger W, Biermann JS, Cohen AD, Devine S, Djulbegovic B, Faber EA Jr, Gasparetto C, Hernandez-Illizaliturri F, Huff CA, Kassim A, Krishnan AY, Liedtke M, Meredith R, Raje N, Schriber J, Singhal S, Somlo G, Stockerl-Goldstein K, Treon SP, Weber D, Yahalom J, Yunus F, Shead DA, Kumar R: Multiple myeloma, version 1.2013. J Natl Compr Canc Netw 2013;11:11-17.

$>7$ Palumbo A, Triolo S, Argentino C, Bringhen S, Dominietto A, Rus C, Omede P, Tarella C, Pileri A, Boccadoro M: Dose-intensive melphalan with stem cell support (MEL100) is superior to standard treatment in elderly myeloma patients. Blood 1999;94:1248-1253.

$>8$ Kumar SK, Dingli D, Lacy MQ, Dispenzieri A, Hayman SR, Buadi FK, Rajkumar SV, Litzow MR, Gertz MA: Autologous stem cell transplantation in patients of 70 years and older with multiple myeloma: results from a matched pair analysis. Am J Hematol 2008;83:614-617.

$>9$ Palumbo A, Gay F, Falco P, Crippa C, Montefusco V, Patriarca F, Rossini F, Caltagirone S, Benevolo G, Pescosta N, Guglielmelli T, Bringhen S, Offidani M, Giuliani N, Petrucci MT, Musto P, Liberati AM, Rossi G, Corradini P, Boccadoro M: Bortezomib as induction before autologous transplantation, followed by lenalidomide as consolidation-maintenance in untreated multiple myeloma patients. J Clin Oncol 2010;28:800-807.
10 Durie BG, Salmon SE: A clinical staging system for multiple myeloma. Correlation of measured myeloma cell mass with presenting clinical features, response to treatment, and survival. Cancer 1975;36:842-854.

11 Greipp PR, San Miguel J, Durie BG, Crowley JJ, Barlogie B, Blade J, Boccadoro M, Child JA, Avet-Loiseau H, Kyle RA, Lahuerta JJ, Ludwig H, Morgan G, Powles R, Shimizu K, Shustik C, Sonneveld P, Tosi P, Turesson I, Westin J: International staging system for multiple myeloma. J Clin Oncol 2005;23:3412-3420.

12 Durie BG, Harousseau JL, Miguel JS, Blade J, Barlogie B, Anderson K, Gertz M, Dimopoulos M, Westin J, Sonneveld P, Ludwig $\mathrm{H}$, Gahrton G, Beksac M, Crowley J, Belch A, Boccadaro M, Cavo M, Turesson I, Joshua D, Vesole D, Kyle R, Alexanian R, Tricot G, Attal M, Merlini G, Powles R, Richardson P, Shimizu K, Tosi P, Morgan G, Rajkumar SV: International uniform response criteria for multiple myeloma. Leukemia 2006;20:1467-1473.

13 Miyakoshi S, Kami M, Yuji K, Matsumura T, Takatoku M, Sasaki M, Narimatsu H, Fujii T, Kawabata M, Taniguchi S, Ozawa K, Oshimi K: Severe pulmonary complications in Japanese patients after bortezomib treatment for refractory multiple myeloma. Blood 2006;107:3492-3494.

14 Combination chemotherapy versus melphalan plus prednisone as treatment for multiple myeloma: an overview of 6,633 patients from 27 randomized trials. Myeloma Trialists' Collaborative Group. J Clin Oncol 1998;16:38323842 .

15 Harousseau JL, Attal M, Avet-Loiseau H, Marit G, Caillot D, Mohty M, Lenain P, Hulin C, Facon T, Casassus P, Michallet M, Maisonneuve $\mathrm{H}$, Benboubker L, Maloisel F, Petillon MO, Webb I, Mathiot C, Moreau P: Bortezomib plus dexamethasone is superior to vincristine plus doxorubicin plus dexamethasone as induction treatment prior to autologous stem-cell transplantation in newly diagnosed multiple myeloma: results of the IFM 2005-01 phase III trial. J Clin Oncol 2010;28:4621-4629.
16 Cavo M, Tacchetti P, Patriarca F, Petrucci MT, Pantani L, Galli M, Di Raimondo F, Crippa C, Zamagni E, Palumbo A, Offidani M, Corradini P, Narni F, Spadano A, Pescosta N, Deliliers GL, Ledda A, Cellini C, Caravita T, Tosi P, Baccarani M, Network GIM: Bortezomib with thalidomide plus dexamethasone compared with thalidomide plus dexamethasone as induction therapy before, and consolidation therapy after, double autologous stem-cell transplantation in newly diagnosed multiple myeloma: a randomised phase 3 study. Lancet 2010;376: 2075-2085.

-17 Sonneveld P, Schmidt-Wolf IG, van der Holt B, El Jarari L, Bertsch U, Salwender H, Zweegman S, Vellenga E, Broyl A, Blau IW, Weisel KC, Wittebol S, Bos GM, StevensKroef M, Scheid C, Pfreundschuh M, Hose D, Jauch A, van der Velde H, Raymakers R, Schaafsma MR, Kersten MJ, van MarwijkKooy M, Duehrsen U, Lindemann W, Wijermans PW, Lokhorst HM, Goldschmidt HM: Bortezomib induction and maintenance treatment in patients with newly diagnosed multiple myeloma: results of the randomized phase III HOVON-65/GMMG-HD4 trial. J Clin Oncol 2012;30:29462955.

18 San Miguel JF, Schlag R, Khuageva NK, Dimopoulos MA, Shpilberg O, Kropff M, Spicka I, Petrucci MT, Palumbo A, Samoilova OS, Dmoszynska A, Abdulkadyrov KM, Schots R, Jiang B, Mateos MV, Anderson KC, Esseltine DL, Liu K, Cakana A, van de Velde H, Richardson PG: Bortezomib plus melphalan and prednisone for initial treatment of multiple myeloma. N Engl J Med 2008;359:906-917. 